\title{
Arte, poética, imagens, visualidades, jovens e performance no acontecimento cotidiano da cidade mundo
}

Art, poetics, images, visualities, the youth and performance around everyday happenings in the world city

\section{Resumo}

Aldo Victorio Filho ${ }^{i}$

Apresento, neste texto, as pesquisas desenvolvidas nos grupos de pesquisa (CNPq) Cultura Visual e Educação (UFG) e Estudos Culturais em Educação e Arte (UFRRJ e UERJ) e no programa de pós-graduação em artes da UERJ tendo como interesse investigativo a cultura visual, os jovens, as produções estéticas não legitimadas pelo sistema outorgado das artes, as poéticas corporais, as performances e performatividades ordinárias e marginais e o ensino formal e informal da arte no cotidiano. Constituir outras fontes epistêmicas que colaborem com a atualização do panorama de entendimento da criação estética, no mais amplo horizonte possível, na vida ordinária e, portanto, na formação humana é também nosso objetivo. Algumas das nossas perspectivas metodológicas e dos nossos referenciais teóricos são focalizados, esperando, dessa forma, abrir novas interlocuções que nos permitam coletivizar o que produzirmos de útil e ajustarmos o que for necessário.

Palavras-chave: cultura visual, jovens, corpos, performance, performatividade.

\begin{abstract}
I present, in this paper, the research developed in the research groups (CNPq) Visual Culture and Education (UFG) and Cultural Studies in Education and Art (UFRRJ and UERJ) and in the graduate program in arts at UERJ having as investigative interest visual culture, youth, aesthetic productions not recognized by the system of institutionalized arts, body poetics, performances and common and marginal performativities, and formal and informal education of art in everyday life. Our objective is also to produce additional epistemic sources that collaborate with the actualization of the panorama of the understanding of aesthetic creation, in a horizon as broad as possible, in ordinary life, and therefore in human formation. Some of our methodological perspectives and theoretical framework have been selected with the hope of thereby opening new dialogues that allow us to collectivize our useful production and adjust what is necessary.
\end{abstract}

Keywords: visual culture, youth, bodies, performance, performativity.

Breve abordagem sobre as pesquisas que venho desenvolvendo no programa de pósgraduação em Artes da Universidade do Estado do Rio de Janeiro, o presente texto é uma pesquisa que se debruça na investigação e discussão sobre os modos juvenis de produzir, poeticamente, e de como esses jovens se relacionam com o mundo imagético visual, como produtores e fruidores. Nosso olhar se dirige, particularmente, aos corpos e à sua permanente continuidade na produção estética cotidiana. Portanto, produção epistêmica que se realiza meio à intensa criação política. 
Com essa rede de pesquisas almejamos discutir e elucidar, na medida do possível, os aspectos que envolvem a figuração estética que os jovens põem em relevo quando se singularizam para dizer o que são e o que territorializam e, por meio das suas imagens, as diferenças que desejam presentes com e em suas vidas. $O$ ponto de partida é a admissão de que, nas escolas, a beleza é uma produção juvenil relativa à intenção da autonomia do estudante frente às práticas de poder que a institucionalização escolar difunde. Em outros termos, a produção estética, especialmente no universo juvenil, é inseparável das movimentações emancipatórias na medida em que são geradas em consonância com a intenção libertadora. No que toca, especificamente, à educação e centralmente ao ensino da arte nos leva, a nós que nos ocupamos desse campo nas universidades, a repensar as tradições e as contradições dos percursos e percalços dos ensinos das Artes na educação básica. Assim, o caminho das pesquisas se pavimenta na perscrutação da produção estética dos praticantes da cidade e nesta, em especial, os jovens nas escolas públicas, e na reflexão sobre os sentidos estético e político da beleza como afirmação juvenil (ALMEIDA, 2006) relativa à busca e ao exercício da autonomia frente às práticas de poder que atravessam e, sob muitos aspectos, se disseminam no cotidiano da cidade para além da escola.

A intensa movimentação de valores e de questionamentos, perplexidades e ressignificações que varrem a contemporaneidade impõem, também, a todas as instituições a reavaliação de seus princípios e de suas práticas. Em face da inegável, intensa e complexa produção de visualidades e sentires desses tempos de agora, o trabalho educacionalmente outorgado para lidar com as imagens e com suas relações e significações estéticas, bem como com o conhecer e proceder artísticos, carecem de enfrentamentos aprofundados com suas questões intestinas, suas histórias, suas atuações e seus desejos de futuro. Para tanto, a favor da atualização da educação pública deflagramos iniciativas de pesquisa que, desdobradas em movimentação de certa amplitude, possam contribuir com o entendimento das forças da estética para além da arte, ou seja, no universo tangível pela existencialidade e olhar, que açambarque tanto a arte quanto qualquer imagem que se relacione, direta ou indiretamente, com a ação estética da vida como obra de arte. Assim, nosso interesse recai, sobretudo, nos fazeres cotidianos que surgem, então, como fontes epistêmicas indispensáveis ao pensamento da educação, dos coletivos e da cidade de hoje.

Os caminhos das pesquisas privilegiam não só a produção estética dos jovens nas escolas públicas, nas quais centralmente perscrutam o sentido estético e político da beleza de suas produções, e como estas se desdobram em outros campos, de igual valor, que acontecem na cidade. Dentre esses caminhos, conduzimos investigações em 
territórios ocultados pelo projeto urbano espelhado nos simulados sucesso social e na saúde. Interessam-nos os desvalidos, os nômades, os marginalizados e o que produzem de saberes, sob o viés imagético nas suas pelejas pelo uso da cidade que thes é, sob muitos aspectos, negada. Também dirigimos nossa atenção aos pacientes do ambulatório psiquiátrico de um hospital público, bem como investigamos produções estéticas de moradores de rua e intervenções poéticas que acontecem, espontaneamente, nos espaços públicos. Ao estudar a força das imagens corpóreas nos cuidados com a aparência pessoal ou os modos de relação coletiva como criação poética defendemos outras fontes de saberes que não só reapresentam o cotidiano como questionam as verdades que the impõem imagens infiéis.

Vista como instituição modelar da modernidade, institucionalmente a escola, assim como os hospitais, reúne os objetivos de produção de indivíduos adequados a finalidades econômicas e sociais restritas. Viver nas escolas implica, para o corpo discente, a adoção de posturas, condutas e ações divergentes, singularizações que desafiam o instituído. Vistas como atuação tática certeauniana, tais ações configuram-se, nas identidades juvenis, mesmo que transitórias forças instituintes de valores, princípios e formas relativamente autônomas ao projeto educativo hegemônico e homogeneizador. Portanto, espaços tempos de saberes vitais à contemporaneidade.

Movimentações que se traduzem em um universo de criações no qual as energias mais notáveis, como já afirmamos, são a estética e a invenção da beleza. Como destacada prática, a produção da beleza adquire uma posição nuclear nos agenciamentos que arrebatam a juventude e daqueles que são realizados nas escolas e demais espaços e tempos nos quais se encontram os meninos e meninas da cidade.

Como beleza nos referimos a toda impressão que visam os jovens por meio do corpo, marcas e gestos que fazem na busca de reverberações para o acontecimento das suas vidas. O interesse é, portanto, relacionar a produção da beleza com a emergência dos novos territórios de embate entre as forças reguladoras contidas nos campos estratégicos, ou seja, outorgados, do sistema e ensino da arte e as potências emancipatórias (SANTOS, 2011) que emergem nos fugazes territórios táticos das relações sociais juvenis - campos de lutas políticas e de lutas sociais característicos da contemporaneidade. Nas quais a estética das relações e ações colaborativas têm notável participação (BOURRIAUD, 2011).

Para a trajetória da aventura investigativa aqui apresentada nos apoiamos em algumas referências imprescindíveis à sua condução: Foucault, com o conceito de estética da 
existência; Maffesoli (2005), com o conceito orgiásmo como força basal do equilíbrio societal; Boaventura S. Santos (2001), com a exploração da tensão entre a regulação e a emancipação como perspectiva de entendimento das sociedades contemporâneas e sua noção de redes de subjetividade; Certeau (1994), com o conceito de estratégia e tática como tensão dinamizadora do cotidiano e finalmente Oliveira e Alves, com a noção da operacionalidade da tessitura; conhecimentos via as redes de subjetividades que se manifestam em cada praticante e em cada prática cotidiana.

Publicadas em artigos e livros, pesquisas reconhecem como fenômeno crescente o protagonismo juvenil na afirmação de valores, conceitos e concepções a respeito do mundo e da própria vida. Este interesse distribuído entre a sociedade civil, o Estado e os organismos internacionais tem articulado políticas para a juventude visando organizar e direcionar todo este cuidado dos jovens com a existência. Sobretudo, o problema do governo das cidades, onde a experiência da escassez e da diversidade (cultural, mas também econômica e social) tem proporcionado uma vigorosa preocupação com a segurança e com a vivência do espaço público, aponta para a importância da disciplina, do controle e da contenção das ações juvenis.

As escolas são instituições privilegiadas da atenção à juventude. Para as escolas são concebidos planos educativos para viver a urbanidade e a pedagogização das condutas na cidade ganha, crescentemente, interesse renovado nos currículos. A admissão de uma performatividade cultural juvenil põe em relevo a apreciação, avaliação, censura e correção dos modos de vida dos estudantes, o que the confere preeminente valor acadêmico e pedagógico. Destaca-se, também, o fato das pesquisas sobre o cotidiano escolar ainda representarem um campo de renovação dos estudos sobre a educação rompendo com as modalidades mais formais de investigação ao buscarem não somente os aspectos mais integrais do poder, mas também da constelação das recusas, contestações e afirmações que nas escolas se ensejam como contradição e luta. Não muito diferente de outras instâncias da cidade (BAUMAN, 2006 e 2009).

Meio à cotidianidade ganha preeminência, por sua vez, as imagens e visualidades, tanto como apresentação de formas de estar e realizar o mundo, como meios de ação e acontecimento social. Nunca, como já reiterado por muitos autores, as imagens e os modos de ver tiveram a movimentação e o destaque na vida cotidiana quanto tem sido nas últimas décadas. Tal evidência respalda o investimento na elucidação das relações e implicações diversas das imagens na formação e atuação das culturas contemporâneas (BHABHA, 1998; CANCLINI, 2008; HALL, 2009). Entendemos, então, como justificável e urgente investigar as juventudes na perspectiva das práticas visuais, produções e 
consumos imagéticos, tomando 'práticas visuais' como modos de ver e buscar ser visto e as produções e consumos imagéticos como todas as relações que envolvam as imagens visuais de urdidura estética. Assim, nos atrai o relacionamento dos jovens com todos os espaços formais ou informais do ensino da Arte, de fruição e criação estética, entendendo esses espaços como campo de embate e criação de modos de resistência e superação; de oposições e antagonismos. Sabemos que os espaços institucionais, dentre os quais as escolas têm, aqui, maior destaque, são conduzidos na defesa de interesses políticos em rede complexa na qual se imbricam aspirações estéticas, pertencimentos culturais, adesões partidárias, volúpias materiais e toda sorte de interesses. Essa rede de múltiplas conexões se escuda, portanto, sob as, muitas vezes discretas, blindagens paradigmáticas forjadas por elementos de resistência e controle de ordem moral, religiosa, sexista, cultural etc. Trata-se de paradigmas surpreendentemente anacrônicos mas que emergem em contraposição ao surgimento de comportamentos e criações (ONFRAY,1999) cada vez mais libertárias, hedonistas e estetizadas. Em oposição, ambas as territorialidades se valem de profícua produção imagética, ou seja, nas contentas da atualidade o jogo das visualidades é de inegável importância para a compreensão de eventos que as teorias de um passado recente logram serventia. Os estudos visuais e demais perspectivas de investigação da Cultura Visual são fundamentais à elucidação do que o mundo atual oferece não só às realizações sociais, mas, sobretudo à formação humana lato sensu, incluindo, certamente, a formação do artista e do cidadão.

Os objetivos das pesquisas são, portanto, de duas ordens: pedagógico e científico. objetivo pedagógico é o de contribuir para os conhecimentos a respeito das criações e ações juvenis nas escolas e a consequente formulação de práticas educativas mais dialógicas e produtivas, afirmando o protagonismo discente vindo a corroborar, dessa forma, com o ideal da autonomia e da liberdade como finalística da educação. O objetivo científico é o de analisar as características da produção política dos jovens nas escolas identificando o que visam, contra o que lutam e o que procuram afirmar; as formas de atuação criadas nessas lutas e como são construídas. Interessam-nos as ações táticas e seus recursos, dentre os quais centramos a atenção nos de ordens estética e imagética. Nas pesquisas dirigidas aos estudantes, e seus cotidianos escolares, dirigimos especial atenção às relações e realizações no âmbito do ensino da Arte. Fora da escola entendemos que se desenvolvem processos de formação que corroboram, ou colidem, com os currículos escolares formais. Entendemos a cidade como maquinário múltiplo que aplica diferentes programas dentre os quais a seleção e legitimação dos praticantes da cidade. Interessam-nos os usos reprimidos, excluídos e evitados. Entendemos que a estetização marginalizada da cidade, pichações, instalações e performances dos sem moradia, e demais habitantes marginalizados das ruas são indícios pregnantes de 
saberes úteis à compreensão da atualidade. Não nos referimos a uma sorte de conhecimento que confirma a atual hierarquia categorial dos sujeitos e da cidade, antes e ao contrário- a um nova ordem de saberes que destitui seus argumentos apartadores e excludentes. Interessa-nos, portanto, corroborar com o enfrentamento das crises da diferença, muitas vezes aporéticas, mas, hoje, inevitáveis.

O desdobramento das nossas pesquisas tem contemplado um leque de investigações sobre tudo o que cerca e enreda as produções estéticas juvenis, no sentido forte e alargado, o que não se refere a intervalos etários, na cidade e nas escolas. Dessa forma, têm destaque as elaborações e discursos curriculares do atual ensino da arte, as visualidades e estéticas corporais, os entendimentos de seus autores e as relações e tensões entre todos esses aspectos nos panoramas diversos que compõem a cidade.

Ao encontro de nosso interesse vêm os estudos do corpo performático, os estudos que se ocupam das estéticas e artes presentes no mundo juvenil, os cotidianos das cidades e das escolas, das cidades como escolas e das escolas como cidades, os estudos das imagens visuais e poéticas imagéticas, as investigações dos discursos a respeito da arte e da estética veiculados pelo ensino oficial da arte, as visões e delírios marginais, as estéticas periferizadas e demais redes de ação e criação que Ihes são correlatas. Alguns dos temas significativos em nossa rede de pesquisa envolvem os currículos oficiais de arte; as produções estéticas juvenis; as visualidades e estéticas da escola e da cidade negada; os corpos como suporte de estéticas identitárias; as tribos e galeras; as iniciativas e projetos escolares no campo da arte e o ensino das artes e suas práticas; as manifestações artísticas e estéticas juvenis; pichação; travestismos; fanzines; músicas; eventos feéricos; artes colaborativas; outsiders; estéticas relacionais etc.

A perspectiva dessa abordagem é de que a vida nas cidades, sobretudo as concernentes aos jovens, hoje, especialmente nas grandes cidades, tem chamado atenção pela presença constante nos acontecimentos nos âmbitos da cultura, do social e da política. Em manifestações artísticas, nos variados novos movimentos sociais ou na militante participação política, os jovens são representantes cada vez mais ativos e numerosos. Percepção cada vez mais conjugada com a ideia de que são eles, sob certas circunstâncias sociais, uma potência perigosa, ameaçadora e à deriva.

Portanto, se por um lado há a percepção de que os jovens podem ser protagonistas privilegiados das ações culturais, econômicas, sociais ou políticas concebidas pelos variados agentes do poder: empresas, o Estado ou organismos internacionais, por outro lado, existe também a sentida necessidade da gestão de uma juventude considerada em 
risco: aquela que vive, de forma mais direta, a experiência da pobreza, a falta de assistência e o sentimento da desesperança com o conseqüente ingresso no estado de anomia social. Apontamos, enfaticamente, as juventudes por representarem os grupos de maior vulnerabilidade, no entanto sabemos, como viemos afirmando, que todas as diferenças, todos os diferentes catalisam a atenção dos que buscam possibilidades epistêmicas adequadas ao entendimento e efetiva participação política na contemporaneidade. Os diferentes são todos os que não se uniformizam em tributação aos sentidos emanados pela hegemonia. São todos os indivíduos e coletivos que produzem suas vidas em consonância com sua culturalidade própria, ainda que esta se entrechoque com as imagens, modos e práticas legitimadas pela hegemonia.

Nas escolas buscamos captar a projeção das ambivalências e ambiguidades dos jovens. $O$ que deles se espera em relação a um ideal social que parcela dominante do mundo adulto fixa. Assim, como buscamos compreender as forças das performatividades e das presenças dos indivíduos que produzem imagens, poéticas e imagens poéticas (MARTINS E TOURINHO, 2012) a contrapelo das legitimações do mundo da arte e da beleza outorgadas como elementos complementares à panoramização da força da Cultura Visual, da produção poética e epistêmica das juventudes. Nossas investigações, agregando a força da presença dos autores do cotidiano para além de interpretações reducionistas às potências das imagens visuais e das formas que os corpos produzem, ao repetir e alterar os cotidianos perscruta como se dá com os jovens estudantes a suposta maturidade. Buscamos identificar as imagens que respaldam a vivência transmitida, por meio dos princípios educativos ensinados, a seleção curricular adotada e a formação concebida, além das regras que são prescritas para a aprendizagem da civilidade dos hábitos, supostamente superiores, que devem ser desenvolvidos. Busca-se elucidar, igualmente, as sanções definidas para a correção dos caminhos seguidos entre as práticas admitidas entendendo que a cidade, também, funciona como maquinário pedagógico programado para coibir, corrigir e dirigir os gestos e os usos dos corpos nos espaços públicos.

Pensar as práticas cotidianas que emergem das interações dos sujeitos com os dispositivos de condução dos corpos e comportamentos na cidade leva a considerar as imagens visuais, criações poéticas, realizações estéticas individuais e coletivas que afloram dessas relações bem como as expectativas em torno da aceitação ou tolerância e a convivência pacífica com a ambição da modelagem e as decorrentes resistências e enfrentamentos. $E$, meio a esse cenário, os entendimentos sobre a beleza e a criação estética desempenham papéis importantes e demandam novas leituras e revisões, 
desconstruções e territorializações viáveis por meio das especificidades das pesquisas que buscamos desenvolver.

O que se assiste nas escolas, assim como em outros espaços de força formativa na cidade, é a irrealização do poder. O que a gestão urbana e a administração escolar cada vez mais reconhecem é a dificuldade para a concretização dos objetivos que a cidade/escola assume e que o programa civilizacional deveria cumprir. Como efeito, assistimos ao conjunto de reações entre a desistência de ensinar, ou pelo menos da desistência de se ensinar como se acredita que deveria, e o recrudescimento dos aparatos de vigilância, controle e punição. Os corpos e a força das suas presenças, quando dissonantes dos referidos programas, são o alvo da coerção e afastamento. De tal modo, que se verifica, com freqüência na agência urbana, o descrédito do diferente e a continuada adoção das formas discricionárias de agir. No que concerne à Educação formal, tal efeito é estendido na particularidade de cada disciplina.. No ensino da arte, que deveria guardar relevante proximidade com os acontecimentos da vida juvenil, aparentemente o estado das artes é o mesmo do macro espaço escolar que, por sua vez, reflete, numa visada de topo, a lógica tensa da cidade.

Não seria o conhecimento sobre o caráter diretivo da educação e o seu largo alcance social o problema preeminente para a consciência adquirida sobre a escola e a condição subalterna de quem é estudante. São as formas de sua inserção social, difusas entre a família, o lazer e a presença nas instituições características da vida juvenil (sobretudo a própria escola) que criarão o ambiente onde se desenvolverá a consciência sobre as atribuições, desempenhos e plenitudes que Ihes são reservados na sociedade, no presente e para a vida adulta.

Portanto, é por meio principalmente dos elementos próximos - práticos e simbólicos - da vida cotidiana que a distribuição desigual do poder na sociedade é pressentida, que o governo de outros indivíduos sobre suas vidas é calculado e os constrangimentos e horizontes das relações sociais são experimentados. É também neste plano, mais imediato, do que é vivido que se desenvolve a virtual faculdade de dirigir a própria vida, mostrando descontentamento com o que parece imposto ou deformador das suas vontades e revelando a disposição para assumir condutas contestatórias e autosuficientes.

Nas escolas, nas cidades, a determinação juvenil se realiza de variados modos, sobretudo comportamental, para demonstrar valores contrários e agir com oposição, sugerindo deserção e afirmando suas diferenças. Nessas práticas, nem sempre notadas, 
não são as formulações discursivas os atos mais pregnantes. É o corpo que tem a preferência dialógica na comunicação juvenil. É com ele que será dito como vêem o mundo e a si próprios, posicionando-se sobre o que é relativo às suas vidas. Corpo ordinariamente natural transformado em um atributo monumental da cultura contemporânea.

A observação do cotidiano nos permitirá um leque de percepção de como os corpos agenciam canais de encontro e linguagens por meio - e através- das imagens que encarnam, criam e dialogam. É o que acontece com a criação de gestos que multiplicam as funções simbólicas do movimento, o que pode ser visto na programação de inúmeras posturas corporais. É também o que ocorre quando se dá a adoção de objetos de consumo como próteses que visam amplificar as realizações dos sentidos. Algo possível de ser notado na posse que fazem dos dispositivos sonoros, informacionais e de comunicação, na exposição e manuseio constante de celulares ou na circulação de books virtuais ou não de fotos. Ou ainda, quando qualidades naturais do corpo se transformam em capacidades superlativas das identidades. Um exemplo é cantar quando as poesias funks enunciadas associam modos de vida e pertencimentos culturais. E é inegavelmente, o jogo criativo da produção estética o que mais se sobressai em suas formas de acontecer, individual e coletivamente (CANEVACCI, 2005).

A idéia central em todas as pesquisas é que o repertório de usos do corpo (NAJMANOVICH, 2001), destinado à ascensão da beleza, à presentificação da existência, à intervenção nos espaços etc. se desenvolve via a gramática estético poética do 'o existir' de valor distintamente político. Embora prevaleçam as ações, aparentemente comuns, e banais, dos sujeitos em repetidas rotinas, impõe-se, no cotidiano, a sua rede de presenças feita de micropolíticas, encontros e desencontros e de sutis montagens das engrenagens do poder. Em relação a esse último aspecto, se percebe, facilmente, entre os meninos e meninas, a freqüente assunção de táticas de resistência e de proclamação de lutas. Ponto privilegiado nas pesquisas é a extensão política destes confrontos e seu significado para a contemporaneidade, sobretudo em face dos discursos veiculados pela educação oficial e ratificados pelos projetos urbanos a respeito da beleza e da atuação estética, pacifismo, adequação comportamental e etc.

Admitir que os fatos a serem analisados e as questões a serem respondidas são complexos, neste mundo simples que é o cotidiano, vai colocar a necessidade de inverter todo o processo aprendido: ao invés de dividir, para analisar, será preciso multiplicar - as teorias, os conceitos, os fatos, as fontes, os métodos etc. Mais que isso, será necessário entre eles estabelecer redes múltiplas e também complexas relações. (ALVES, 2001, 
No espaço e tempo da pesquisa no/do cotidiano, nos quais a interrogação dos sentidos que damos à pesquisa é permanente, não há refúgio teórico nem prático que separe os olhos dos que vêem daquilo ou daqueles que são vistos. Em outras palavras, em qualquer pesquisa nessa órbita o pesquisador é, inexoravelmente, inseparável daquilo que investiga.

Considerando que professores e professoras, estudantes, artistas e não artistas e homens e mulheres comuns estão dinamicamente enredados nas tragédias e comédias do dia-a-dia, o desafio da pesquisa no cotidiano reside, inicialmente, na dificuldade e risco da escolha das formas e dos meios pelos quais se darão os processos investigativos que abordarão sujeitos enredados com tantas histórias, imagens, poéticas e demais afetos em tantas diferentes redes de situações. É preciso escolher cuidadosamente o primeiro passo, e para este primeiro movimento, a isenção, a imparcialidade e a neutralidade se revelam posicionamentos impossíveis em face das surpresas e demais peculiaridades cotidianas, sobretudo, aquelas que marcam os envolvimentos que acabam por ligar os pesquisadores aos seus temas e interlocutores. Sob essa perspectiva, o respaldo da mítica rigidez da exatidão científica, assim como a maioria das técnicas tradicionais da etnografia moderna, sem serem desconsideradas, tem sua utilidade fatalmente reduzida.

A dimensão do desafio metodológico é vislumbrada na medida em que é preciso se dar conta de que para alcançar a desejada aproximação com o cotidiano não se pode contar com o recurso das técnicas disciplinares tradicionais que são armadas pelo rigor metodológico. Por outro lado, conforme propõe Oliveira (2003, p.72 e 73),

se nos mantermos excessivamente ligados a premissas predefinidas a respeito do que pretendemos pesquisar, em função daquilo que acreditamos já saber, criamos, em nossas redes, "nós cegos", que subtraem dela algo de sua maleabilidade e, portanto, da possibilidade de entradas e articulações de novos fios de saberes ao anteriormente sabido.

Porque nesse modo de pesquisar a flexibilidade das ações investigativas deve ser permanente para que se possa dialogar com as sucessões de acontecimentos que vibram o cotidiano e cujas relações não se mostram imediatamente claras, visto que os canais de ligação entre este ou aquele fato são rizomáticos, muitas vezes subterrâneos, muitas vezes invisíveis ao olhar interrompido na superfície das práticas. Como esclarece Maffesoli (2005, p.104): 
... a efervescência epistemológica perceptível em nossas disciplinas acadêmicas é o indicador mais claro dos diversos deslocamentos em ação nas sociedades contemporâneas. È inútil retomar a saturação dos grandes sistemas explicativos, pois isso agora é uma evidência. Em ricochete isso fragilizou as certezas metodológicas e as grades de leitura preestabelecidas e aplicadas a priori em qualquer situação social.

Da rede de ações que norteiam a pesquisa destacamos cinco elementos centrais que não se diagramam em ordenação hierárquica: a poética da vida dos praticantes da cena investigada; o afeto que nos (nós professores/pesquisadores) liga ao ambiente da investigação ou investigado; o possível aproveitamento dos resultados deste trabalho na ajuda aos que lá estão (FERRAÇO, 2003, p.72); o diálogo aberto com os protagonistas e com as imagens que oferecem, lidam e ou produzem e finalmente, o redimensionamento, a todo o momento, das distâncias entre o pesquisador e o campo pesquisado, procurando não perder a noção da complexidade e da riqueza das ações de seus praticantes.

O elemento norteador da metodologia pretendida é a força do cotidiano, ou seja, a poética que emana da própria ambiência da pesquisa: o acontecimento da vida dos sujeitos protagonistas deste cotidiano. Explorar a potência do cotidiano seria impensável sob a tutela de abordagens e registros guiados por qualquer unidade metodológica rígida pois, para a nossa aventura investigativa, a idéia de uma metodologia concebida e estruturada em procedimentos regulares não levaria além da paisagem ilusória de uma tradução limitadora/redutória de algo que prima pelo constante transbordamento de seus próprios limites.

O método, ou o caminho proposto, acontece destituído da pretensão de cristalização teórica, ou seja, da possibilidade de transmutação de sua experiência singular para um esquema acabado que possa ser aplicado, automaticamente, a outras pesquisas.

Uma das maneiras de investigar o cotidiano da cidade é via sua prolífera produção imagética, trajetória, esta, privilegiada em quase todas as nossas pesquisas, por acreditarmos que diante do olhar e sentir desarmados, e em conjunção com a curiosidade livre, os praticantes do cotidiano das cidades e de suas instituições revelam suas peculiaridades, suas estéticas e suas singularidades que, em conexões surpreendentes, constituem novas fontes de saber sobre o presente de todos nós.

Consideramos como um dos elementos, ou princípio caro à criação metodológica, o cuidado em não separar a imagem imaterial, produto da imaginação, das imagens materiais, defendendo que as segundas não se reduzem à sua materialidade, pois têm 
sempre relação direta com as primeiras. As imagens materiais guardam proveitosos conteúdos indiciários (GINZBURG, 1989) da permanente produção imaginária que permite a existência das instituições em que habitam, ou representam, e, sobretudo, dos sentidos das práticas que as constituem. Assim, os modos, as práticas, as imagens, as poéticas individuais e coletivas dos atores da vida cotidiana evidenciam - objetiva ou sub-repticiamente - o que se pretende e o que fazemos do mundo.

\section{Rede teórica: o mistério da conjunção e a invenção do cotidiano}

O paradigma cultural para o qual o mundo estaria retornando à fase tribal afirma haver um retorno de valores que a modernidade houvera dispensado e ou julgava terem se perdido. A pós-modernidade seria, então, marcada pelo aspecto emocional e restabeleceria a sensibilidade espontânea e franca meio às novas gerações. Michel Maffesoli (O tempo das Tribos, 2000), explicaria o novo paradigma que viria substituir as leis do individualismo na conformação da sociedade contemporânea, pois ele está "baseado na necessidade de solidariedade e de proteção que caracterizam o conjunto social".

A metáfora tribo, (idem, 2000) nos permite dar conta do processo de desindividualização e do papel de cada pessoa; aqui reconhece a idéia da "persona", da máscara que pode ser mutável e que integra, sobretudo, uma variedade de cenas, de situações que só valem porque são representadas dentro de uma tribo. Existe essa fluidez desses tempos pós modernos que faz com que essas novas tribos se ajuntem.

O pensador chama essa multiplicidade de "paradigma estético" no sentido de vivenciar ou de sentir em comum. Pois, nessa perspectiva, que muito interessa às pesquisas realizadas, só há existência concreta na relação com o outro. Não se trataria só da história que algum indivíduo constrói associado a outros indivíduos racionais, mas de um "mito do qual participo" Uma realização poética, estética que afirma a existência do corpo social ao qual pertencemos. Esses mitos ou obras podem ser os heróis, santos, figuras emblemáticas, mas o mais importante é permitirem que qualquer um venha a se reconhecer com os outros. Assim, as figuras míticas, ou os tipos sociais, viabilizam uma "estética" comum e que servem de receptáculo à expressão do nós.

O princípio de individuação, de separação, estes, pelo contrário, são dominados pela indiferenciação, pelo perder-se em um sujeito coletivo que, diferente de um pertencimento orgânico sensorial, acontece no ritmo entorpecido das manadas, o que seria um tribalismo destribalizado. Segundo o autor, a sociedade é constituída por diversos tribalismos que podem ser de vários tons e motes condutores: esportivos, hedonistas, religiosos, musicais, tecnológicos, sendo uma "comunidade emocional" ou 
"nebulosa afetiva" que vai se exprimir numa sucessão de ambiências, de sentimentos, de emoções, típico da sociedade moderna de acordo com o ethos (éthos: conjunto dos costumes e hábitos fundamentais, no âmbito do comportamento (instituições, afazeres...) e da cultura (valores, idéias ou crenças), característicos de uma determinada coletividade, época ou região), comunitário. O tribalismo refere-se a uma vontade de "estar junto", onde o que importa é o compartilhamento de emoções em comum.

A sensibilidade coletiva, por um lado, está ligada ao espaço próximo e, por outro, transcende ao próprio grupo e o situa numa "linhagem" que se pode compreender, seja stricto sensu, seja em uma perspectiva imaginária. Emoção, sentimento, mitologia e a sensibilidade coletiva, ultrapassando a atomização individual, suscitariam as condições de possibilidade para uma espécie de energia revitalizadora que particularizaria a atualidade.

Michel de Certeau revigora a vida cotidiana como fonte de saberes ampliadores do panorama elucidado pelas ciências sociais tradicionais. A vida cotidiana, tida comumente como inércia e ou rotina, fora levada a não constituir temática nobre para as ciências muito menos a criar especialistas ou cientistas sociais. Somente, via o exercício de inquietação crítica que punha em questão as grandes teorias sociais e demais construções abstratas que o tema do cotidiano viria a ganhar relevância nas ciências humanas e isso há bem pouco tempo. O referido esforço intelectual que respaldaria o estudo do cotidiano teria sido ativado por recentes experiências históricas nas quais acontecimentos no âmbito cultural passaram a ser reconhecidos como motivadores de mudanças sociais.

Publicado originalmente em 1980, "A Invenção do Cotidiano", de Michel de Certeau é um livro pioneiro e fundamental na aventura filosófica de desvendamento das práticas culturais contemporâneas vistas, aí, não mais pelo ângulo elitista da razão técnica e produtivista, mas pelo lado supostamente mais fraco da produção cultural: o da recepção anônima, da cultura ordinária, da criatividade das pessoas comuns.

Pela argumentação acima, lançar mão da obra de Certeau, não seria por qualquer equivocada pegada superficial do popular, pois sua obra, significativamente representada no livro "A invenção do cotidiano", não permite ingenuidades na abordagem de quaisquer aspectos que envolvam o popular. A referência dessa obra, cujo autor se mostra profundamente insatisfeito com as teorias sociais que pintam o quadro de uma sociedade estruturada em papéis abstratos e estereótipos, procura esboçar uma teoria das práticas cotidianas e identificar uma espécie de lógica operatória nas culturas populares, o que 
vem, de forma feliz, ao encontro das perspectivas da pesquisa, uma vez que esta segue a contrapelo do hegemônico via a lógica da teimosia fundada, quase que, apenas no real. Real, este, captado mais sensorialmente do que hermeneuticamente, pois recusa a escrita como espaço da dominação e do controle; lógica do informal, porque ressalta a importância da utilização das táticas no jogo inevitável das estratégias; lógica do instável, uma vez que, sem lastros assegurados ou âncoras fiéis é centrada nas operações de caça. A utilidade do pensamento certeauniano na pesquisa é assegurada na lógica da "arte de fazer", pois as experiências do homem ordinário não se deixam aprisionar pela limitação da linguagem escrita: quer se trate da voz do selvagem, dos primeiros relatos etnográficos, do ato de assistir TV ou de enveredar pelas inesperadas ruas das grandes cidades. Certeau auxilia na busca da lógica cujos modelos remontam, talvez, às astúcias multimilenares dos peixes disfarçados ou dos insetos camuflados e que, em todo caso, é ocultada por uma racionalidade hoje dominante no Ocidente. Por isso, busca exemplos em tradições, provérbios e atitudes que a cientificidade do Ocidente ocultou: a "Arte da Guerra" de Sun Tze, da tradição chinesa; ou o "Livro das Astúcias", da tradição árabe.

Nem o marxismo, nem as concepções liberais, com suas ambições totalizantes, foram capazes de perceber na vida cotidiana este espaço de gestação de processos alternativos, de esperteza e de inventividade, que se forja a revelia dos cerrados processos de hegemonia e dominação na modernidade. Certeau oferece os necessários malabarismos teóricos para uma rede de aproveitamento conceitual que conecta Freud, Foucault e Bourdieu, mas parece encontrar inspiração nos inquietantes fragmentos de Wittgenstein. Provavelmente porque, tal como o "homem ordinário" de Wittgenstein, o pensador e historiador soubesse que a página em branco é um lugar desenfeitiçado das ambiguidades do mundo e que as narrativas do cotidiano seriam incomparavelmente mais próximas da intensidade da concretude da vida do que qualquer sofisticação textual realizada em gabinetes isolados do burburinho das ruas e demais espaços praticados pelos homens comuns. Tal como os espaços das ruas, das escolas públicas, dos cabeleireiros nas periferias da cidade, e demais zonas mal afamadas sobres os quais se desdobram nossas elocubrações.

\section{Referências}

ALMEIDA, Maria Isabel Mendes de e EUGENIO, Fernanda (orgs.). Culturas jovens: novos mapas do afeto. Rio de Janeiro: Jorge Zahar Ed., 2006.

ALVES, Nilda e OLIVEIRA, Inês Barbosa de. Pesquisa no/do cotidiano das escolas: sobre rede de saberes. Rio de Janeiro: DP\&A, 2001. 
BAUMAN, Zygmunt. Confiança e medo na cidade. Rio de Janeiro: Jorge Zahar Ed., 2009.

. Modernidade Líquida. Rio de Janeiro: Zahar, 2001.

BHABHA, Homi K.. O local da cultura. Belo Horizonte: Ed. UFMG, 1998.

BOURRIAUD, Nicolas. Radicante: por uma estética da globalização. São Paulo: Martins Fontes, 2011.

CANCLINI, Néstor Garcia. Imaginários Culturais da Cidade: Conhecimento/Espetáculo/Desconhecimento. In: A cultura pela cidade. Teixeira

Coelho (org). São Paulo: Iluminuras: Itaú Cultural, 2008.

CANEVACCI, Massimo. Culturas eXtremas: mutações juvenis nos corpos das metrópoles. Rio de Janeiro: DP\&A, 2005.

CERTEAU, Michel de. A invenção do cotidiano. Petrópolis, RJ : Vozes, 1994.

CORAZZA, Sandra Mara. Para uma filosofia do inferno na educação: Nietzsche, Deleuze e outros malditos afins. Belo Horizonte: Autêntica, 2002.

2006.

Artistagens - filosofia da diferença e educação. Belo Horizonte: Autêntica,

DIAS, Souza. Lógica do acontecimento: Deleuze e a filosofia. Porto: Afrontamento, 1995.

GINZBURG, Carlo. Mitos, emblemas e sinais: morfologia e história. São Paulo: Companhia das Letras, 1989.

GUIMARÃES, Antonio Monteiro (org). As Bodas de Fígaro: Mozart, da Ponte, Beaumarchais. Rio de Janeiro: Jorge Zahar Ed., 1991.

HEINRICH, Bettina. Mudando cidades: um novo papel para a política cultural urbana. In: A cultura pela cidade. Teixeira Coelho (org). São Paulo: Iluminuras: Itaú Cultural, 2008.

HALL, Stuart. A identidade cultural na pós-modernidade. Rio de Janeiro: DP\&A, 2006.

UFMG, 2009.

Da diáspora: identidades e mediações culturais. Belo Horizonte: Editora

MAFFESOLI, $\mathbf{O}$ mistério da conjunção: ensaios sobre comunicação, corpo e sociedade. Porto Alegre: Sulina, 2005.

MAFFESOLI, Michel. A Sombra de Dionísio: contribuição a uma sociologia da orgia. São Paulo: Zouk, 2005.

O mistério da conjunção. Porto Alegre: Sulina, 2005.

O tempo das tribos: o declínio do individualismo nas sociedades de massa. Rio de Janeiro: Forense Universitária, 2000.

MARTINS, Raimundo e TOURINHO, Irene (orgs) Cultura das imagens - desafios para a arte e para a educação. Santa Maria (RS): UFSM, 2012. 
NAJMANOVICH, Denise. O sujeito encarnado: questões para pesquisa no/do cotidiano. Rio de Janeiro: DP\&A, 2001.

ONFRAY, Michel. A arte de ter prazer: por um materialismo hedonista. São Paulo: Martins Fontes, 1999.

SANTOS, Boaventura de Sousa. Crítica da razão indolente A - Contra o desperdício da experiência. São Paulo: Cortez, 2011.

' Professor Adjunto do Instituto de Artes da Universidade Estadual do Rio de Janeiro, UERJ. avictorio@gmail.com

Recebido em: 23/09/2013

Aprovado em: 15/10/2013 